\title{
RESEARCH
}

Open Access

\section{The association of $A P O E \varepsilon 4$ with cognitive function over the adult life course and incidence of dementia: 20 years follow-up of the Whitehall II study}

Amin Gharbi-Meliani ${ }^{1}$, Aline Dugravot ${ }^{1}$, Séverine Sabia ${ }^{1}$, Melina Regy ${ }^{1}$, Aurore Fayosse ${ }^{1}$, Alexis Schnitzler ${ }^{1}$, Mika Kivimäki ${ }^{2}$, Archana Singh-Manoux ${ }^{1,2}$ and Julien Dumurgier ${ }^{1,3^{*}}$ (i)

\begin{abstract}
Background: Approximately $25 \%$ of the general population carries at least one $\varepsilon 4$ allele of the Apolipoprotein $\mathrm{E}$ $(A P O E \varepsilon 4)$, the strongest genetic risk factor for late onset Alzheimer's disease. Beyond its association with late-onset dementia, the association between APOE $\varepsilon 4$ and change in cognition over the adult life course remains uncertain. This study aims to examine whether the association between Apolipoprotein E (APOE) $\varepsilon 4$ zygosity and cognition function is modified between midlife and old age.

Methods: A cohort study of 5561 participants (mean age 55.5 (SD = 5.9) years, 27.1\% women) with APOE genotyping and repeated cognitive tests for reasoning, memory, and semantic and phonemic fluency, during a mean (SD) follow-up of 20.2 (2.8) years (the Whitehall II study). We used joint models to examine the association of APOE genotype with cognitive function trajectories between 45 and 85 years taking drop-out, dementia, and death into account and Fine and Gray models to examine associations with dementia.

Results: Compared to non-carriers, heterozygote (prevalence 25\%) and homozygote (prevalence 2\%) APOE ع4 carriers had increased risk of dementia, sub-distribution hazard ratios $2.19(95 \% \mathrm{Cl} 1.73,2.77)$ and $5.97(95 \% \mathrm{Cl} 3.85$, 9.28) respectively. Using data spanning $45-85$ years with non- $\varepsilon 4$ carriers as the reference, $\varepsilon 4$ homozygotes had poorer global cognitive score starting from 65 years; $\varepsilon 4$ heterozygotes had better scores between 45 and 55 years, then no difference until poorer cognitive scores from 75 years onwards. In analysis of individual cognitive tests, better cognitive performance in the younger $\varepsilon 4$ heterozygotes was primarily attributable to executive function.

Conclusions: Both heterozygous and homozygous $\varepsilon 4$ carriers had poorer cognition and greater risk of dementia at older ages. Our findings show some support for a complex antagonist pleiotropic effect of APOE $\varepsilon 4$ heterozygosity over the adult life course, characterized by cognitive advantage in midlife.
\end{abstract}

Keywords: Apolipoprotein E, Cognitive aging, Cohort study, Dementia, Alzheimer's disease

\footnotetext{
* Correspondence: julien.dumurgier@inserm.fr

'Université de Paris, Inserm U1153, Epidemiology of Ageing and

Neurodegenerative Diseases, Paris, France

${ }^{3}$ Cognitive Neurology Center, Lariboisiere - Fernand Widal Hospital, AP-HP, Université de Paris, 200 rue du Faubourg Saint Denis, 75010 Paris, France

Full list of author information is available at the end of the article
}

C C The Author(s). 2021 Open Access This article is licensed under a Creative Commons Attribution 4.0 International License, which permits use, sharing, adaptation, distribution and reproduction in any medium or format, as long as you give appropriate credit to the original author(s) and the source, provide a link to the Creative Commons licence, and indicate if changes were made. The images or other third party material in this article are included in the article's Creative Commons licence, unless indicated otherwise in a credit line to the material. If material is not included in the article's Creative Commons licence and your intended use is not permitted by statutory regulation or exceeds the permitted use, you will need to obtain permission directly from the copyright holder. To view a copy of this licence, visit http://creativecommons.org/licenses/by/4.0/ The Creative Commons Public Domain Dedication waiver (http://creativecommons.org/publicdomain/zero/1.0/) applies to the data made available in this article, unless otherwise stated in a credit line to the data. 


\section{Background}

The $\varepsilon 4$ allele of the Apolipoprotein $\mathrm{E}(A P O E)$ gene is the strongest genetic risk factor for late onset Alzheimer's disease (AD) [1]. Around 25\% of the Caucasian population carries at least one $\varepsilon 4$ allele [2], with a 3-fold increased risk of $\mathrm{AD}$ for heterozygotes and a nearly 15fold increased risk for homozygotes compared to the $\varepsilon 3$ homozygotes, the most common genotype [3]. APOE $\varepsilon 2$ is less common and appears to have a protective effect on $\mathrm{AD}$ [4]. The mechanisms underlying the relationship between $A P O E \& 4$ and $\mathrm{AD}$ are thought to be complex [5], involving, e.g., $\beta$-amyloid $(\mathrm{A} \beta)$ peptide clearance [6], neuronal death [7], and phosphorylation of tau [8].

In addition to $\mathrm{AD}, A P O E \& 4$ plays a role in other causes of dementia, including vascular dementia [9], and Lewy Body disease [10]. Although case-control and longitudinal studies have examined the association of $A P O E$ with dementia, its association with cognitive decline over the adult life course remains debated [11, 12]. Some studies show accelerated cognitive decline in $A P O E \& 4$ homozygotes but not heterozygotes [13-15]. Furthermore, the association between $A P O E \varepsilon 4$ and cognition is thought to be modified by age; some [16-18] but not all studies $[19,20]$ report better cognitive performance among $\varepsilon 4$ carriers at younger ages. The antagonistic pleiotropy hypothesis $[21,22]$, whereby a gene is thought to have different effects on health during different life stages, is a possible explanation for the age-varying association of $A P O E \& 4$ with cognitive performance over the life course [18, 22, 23]. However, much of the research on $A P O E$ is based on adults older than 65 years, followed for less than 10 years, making it difficult to ascertain how $A P O E$ shapes cognitive performance over the life course.

To address some of these limitations, we examined the relationship of homozygotes and heterozygotes $A P O E \varepsilon 4$ with cognitive decline from midlife to old age and incident dementia. The analysis of dementia takes competing risk of death into account and that for cognitive decline takes mortality, dementia, and drop-out into account using joint models.

\section{Methods}

\section{Study population}

The Whitehall II Study is an ongoing cohort study of persons originally employed by the British Civil Service, full details of which have been reported previously [24]. A total of 10,308 persons aged $35-55$ years (67\% male) were recruited to the study between 1985 and 1988 and have undergone clinical examination every 4 to 5 years. The baseline of the present study is 1997-1999 when a cognitive test battery was added to the protocol and repeated in 2002-2004, 2007-2009, 2012-2013, and 2015-2017.

\section{Cognitive function}

The cognitive test battery, administered 5 times between 1997-1999 and 2015-2017, which consisted of 4 tests. Memory: participants were presented with a 20-word list of one or two syllable words at two second intervals, with 2 min time to write down as many words as they can recall, regardless of word order. Reasoning: participants had $10 \mathrm{~min}$ to complete the AH4-I (Alice Heim 4I), a series of 65 verbal and mathematical reasoning items of increasing difficulty [25]. Verbal fluency: phonemic fluency was assessed via "S" words and semantic fluency via "animal" words tests. One minute was allowed for each test. To allow comparison between tests, we standardized all raw test scores to $z$-scores ( mean $=0$, standard deviation $[\mathrm{SD}]=1$ ). These $z$-scores were summed and re-standardized to yield the global cognitive score, a method that minimizes measurement error [26].

\section{Dementia}

Dementia diagnosis was derived from three comprehensive electronic health records through to March 2019 [27]: NHS Digital's Hospital Episode Statistics (HES) and Mental Health Services Data (MHDS), which include clinical diagnoses recorded during routine clinical contact in inpatient, outpatient, and community care in the NHS, including memory clinics, and the mortality register. The following ICD-10 codes were used for diagnosis of all-cause dementia: F00x-F03x, F05.1, and G30xG31.0.

\section{APOE genotyping}

DNA was extracted from whole blood samples, drawn at the 1997-1999 clinical examination. Two TaqMan assays (Rs429358 and Rs7412, Assay-On-Demand, Applied Biosystems) were used and run on a $7900 \mathrm{HT}$ analyzer (Applied Biosystems) and genotypes indicated by the Sequence Detection Software version 2.0 (Applied Biosystems). Genotyping was repeated for 511 participants and error rates were found to be lower than $0.15 \%$ [28].

\section{Covariates}

Sociodemographic variables included age at baseline (1997-1999 examination), sex, marital status (married/ cohabiting vs others), socioeconomic status using employment grade (three categories: high, intermediate, and low representing income and status at work), and education (three categories: lower secondary school, higher secondary school, and university/higher university degree).

\section{Statistical analysis}

The current analyses were based on Caucasians, with data on $A P O E$ genotype and at least one measure of 
cognitive function. Baseline characteristics are presented for the analytic sample, by $A P O E$ genotype, and according to the occurrence (yes/no) of dementia or death during the follow-up. Proportions were calculated for categorical variables, while means and standard deviations were computed for continuous variables. Comparisons between groups were assessed using a $\chi^{2}$ test or analysis of variance as appropriate.

$A P O E$ was modeled as a function of the number of $\varepsilon 4$ alleles $(0,1$, or 2$)$ and in detailed categories with $\varepsilon 2, \varepsilon 3$, and $\varepsilon 4$ alleles. We first examined the association between $A P O E$ genotypes and incident dementia using Fine and Gray models for sub-distribution hazard ratio (SHR), to take into account the competing risk of death [29]. Age was considered as the time scale and participants were censored at onset of dementia, death, or end of follow-up (March 31, 2019), whichever came first. The initial model was adjusted for age (as time scale) and birth cohort (using 5-year categories) and subsequently for sex, education, marital status, and occupation.

We analyzed the relationship between $A P O E$ genotypes and cognitive decline using linear mixed models with age as time scale (age, age ${ }^{2}$, and age ${ }^{3}$ to model nonlinear change). These models were adjusted for sex and its interaction with time and birth cohort, and both intercept and slope were fitted as random effects with unstructured covariance matrix. We used a joint modeling approach with the stjm command in Stata to model jointly cognitive decline (with initial linear mixed model) and time to exit from the follow-up, set at the earliest date from drop-out, dementia, or death (with a flexible parametric model). This approach links sub-models by including shared random effects that allow for dependency between the longitudinal process and time to dropout, dementia, or death. We then estimated marginal predictions to determine the difference in cognitive function between $A P O E$ \&4 carriers compared to noncarriers at different ages between 45 and 85 years. Analyses were performed for the global cognitive score and repeated for each of the 4 cognitive tests. In sensitivity analysis, we reran the joint model after excluding all cases of dementia to test the robustness of the association between $A P O E$ genotypes and cognitive decline.

Two-tailed values of $p<0.05$ were considered statistically significant. Analyses were performed using Stata 15 (StataCorp LP, College Station, TX).

\section{Results}

\section{Demographic characteristics}

A total of 7870 participants were included in the 19971999 clinical examination. Among them, 1784 were excluded from the present study due to missing data on $A P O E$ genotype and 45 for missing cognitive data. A further 480 participants were excluded as they were non-Caucasian; flow-chart of the study is presented in Fig. 1. A total of 5561 participants were included in the analysis, with a mean (SD) follow-up of 20.0 (2.8) years, corresponding to 111,132 person-years of follow-up.

Table 1 summarizes participants' baseline characteristics, overall and by $A P O E$ genotype. Their mean (SD) age at start of the follow-up was 55.5 (5.9) years and $27 \%$ of them were women. The frequency of the alleles $\varepsilon 2$, $\varepsilon 3$, and $\varepsilon 4$ was respectively $8 \%, 77 \%$, and $15 \%$ in the study population. Fifty-nine percent of the study population were $A P O E \varepsilon 3 / \varepsilon 3$ homozygous, $27 \%$ carried at least one $\varepsilon 4$ allele (heterozygotes $25 \%$, homozygotes $2 \%$ ), and $13 \%$ were either $\varepsilon 2 / \varepsilon 2(0.6 \%)$ or $\varepsilon 2 / \varepsilon 3(12.4 \%)$. No differences in term of socio-demographic characteristics were observed according to APOE genotype. Compared to $\varepsilon 3 /$ $\varepsilon 3$ participants (Additional file 1: Table S1), $\varepsilon 2 / \varepsilon 2$ group had higher scores on memory $(p=0.035)$, phonemic fluency $(p=0.049)$, and semantic fluency $(p=0.049)$. The $\varepsilon 3 / \varepsilon 4$ group also had higher scores on reasoning ( $p=$ $0.032)$ and phonemic fluency $(p=0.028)$ than $\varepsilon 3 / \varepsilon 3$ homozygous. There was no difference in cognitive scores at baseline between the $A P O E \quad \varepsilon 4 / \varepsilon 4$ and $\varepsilon 3 / \varepsilon 3$ homozygotes.

\section{Association of APOE genotype and dementia}

Table 2 presents baseline sample characteristics as a function of dementia and vital status over the follow-up. The 310 participants who developed dementia were older, were more often women, had a lower education level, had poorer cognitive performance, and were more likely to carry at least one $A P O E \& 4$ allele ( $46 \%$ vs $27 \%$, $p<0.001)$. Seven hundred seventy-eight participants died during the follow-up. They were older, were more often single, and had a lower education level and poorer cognitive test scores.

The association between $A P O E$ genotype and incident dementia, mean follow-up 20.0 (2.8) years, is presented in Table 3. Compared to non- $\varepsilon 4$ carriers, the presence of $\varepsilon 4$ allele was associated with an increased risk of dementia for both heterozygotes (SHR 2.19; 95\% confidence interval 1.73 to 2.77 ) and homozygotes $(5.97 ; 3.85$ to 9.28), after adjustment for age and birth cohort. Further adjustment for sex, education, marital status, and occupation did not modify these associations.

\section{APOE genotype and cognitive function trajectories}

A total of $0.4 \%$ participants dropped-out after the first wave of cognitive data collection, $9.1 \%$ after the second wave, $8.7 \%$ after the third wave, and $11.8 \%$ after the fourth wave; $69.9 \%$ of participants included in the analyses provided data at all waves. Participants with fewer follow-up examinations were more likely to be older, women, and less educated and had lower cognitive 


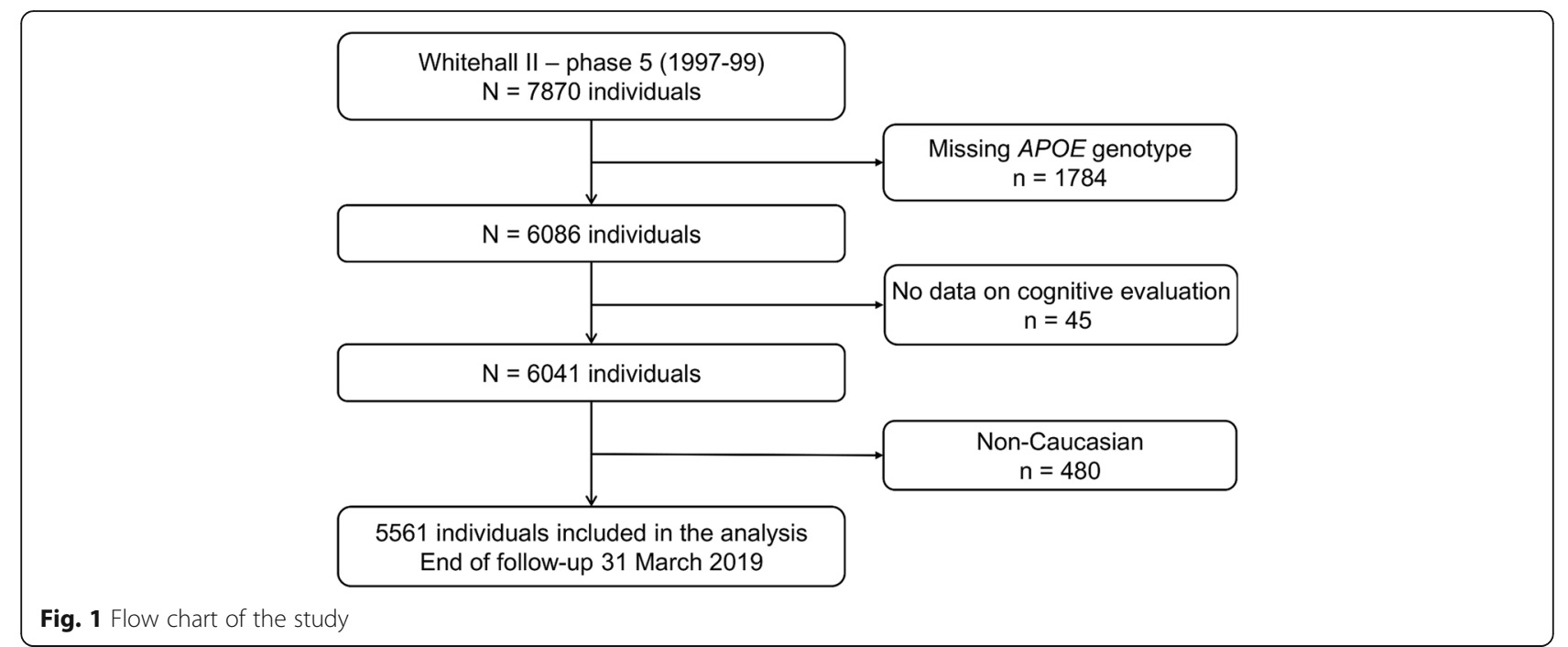

scores at baseline. APOE \&4 status was not associated with participation over the follow-up (Additional file 2: Table S2).

Trajectories of the global cognitive score between 45 and 85 years as a function of the number of APOE $\varepsilon 4$ alleles (no- $\varepsilon 4$, heterozygotes, and homozygotes) are presented in Fig. 2a. Overall, the global cognitive score declined with age in all the three groups $(p<0.001)$.
Compared to non- $\varepsilon 4$ carriers, $\varepsilon 4$ homozygotes had poorer global cognitive score from 65 years onwards (Fig. 2b, Table 4). $\varepsilon 4$ heterozygotes had better performances than non- $\varepsilon 4$ carriers between 45 and 55 years, then no differences between 60 and 70 years, and poorer performance from 75 years onwards (Fig. 2b, Table 4). Further detailed analysis (Additional file 3: Table S3) showed the group $(\varepsilon 2 / \varepsilon 2$, $\varepsilon 2 / \varepsilon 3)$ to have better cognitive

Table 1 Baseline characteristics overall and by APOE genotype

\begin{tabular}{|c|c|c|c|c|c|c|c|c|}
\hline \multirow[t]{2}{*}{ Sample characteristics } & \multicolumn{7}{|c|}{ APOE genotype } & \multirow[t]{2}{*}{$p$ value } \\
\hline & $\begin{array}{l}\text { All } \\
(n=5561)\end{array}$ & $\begin{array}{l}\varepsilon 2 \varepsilon 2 \\
(n=33)\end{array}$ & $\begin{array}{l}\varepsilon 2 \varepsilon 3 \\
(n=691)\end{array}$ & $\begin{array}{l}\varepsilon 3 \varepsilon 3 \\
(n=3296)\end{array}$ & $\begin{array}{l}\varepsilon 2 \varepsilon 4 \\
(n=139)\end{array}$ & $\begin{array}{l}\varepsilon 3 \varepsilon 4 \\
(n=1273)\end{array}$ & $\begin{array}{l}\varepsilon 4 \varepsilon 4 \\
(n=129)\end{array}$ & \\
\hline Age, years, mean (SD) & $55.5(5.9)$ & $56.4(5.6)$ & $55.8(6.2)$ & $55.6(5.9)$ & $55.1(5.9)$ & $55.5(6.0)$ & $55.1(6.0)$ & 0.64 \\
\hline Women, $n$ (\%) & $1508(27.1)$ & $10(30.3)$ & $175(25.3)$ & $930(28.2)$ & $33(23.7)$ & $327(25.7)$ & $33(25.6)$ & 0.35 \\
\hline Married/cohabiting, $n(\%)$ & $4256(76.5)$ & $25(75.8)$ & $528(76.4)$ & $2524(76.6)$ & $103(74.1)$ & $977(76.8)$ & $99(76.7)$ & 0.99 \\
\hline \multicolumn{9}{|l|}{ Education level, $n$ (\%) } \\
\hline Lower secondary school & $2384(42.9)$ & $10(30.3)$ & $294(42.6)$ & $1423(43.2)$ & $47(33.8)$ & $565(44.4)$ & $45(34.9)$ & \\
\hline Higher secondary school & $1524(27.4)$ & $12(36.4)$ & $191(27.6)$ & $920(27.9)$ & $42(30.2)$ & $324(25.4)$ & $35(27.1)$ & \\
\hline University degree or higher & $1653(29.7)$ & $11(33.3)$ & $206(29.8)$ & $953(28.9)$ & $50(36.0)$ & $384(30.2)$ & $49(38.0)$ & 0.11 \\
\hline \multicolumn{9}{|l|}{ Occupation, n (\%) } \\
\hline Low & $557(10.0)$ & $3(9.1)$ & $60(8.7)$ & $336(10.2)$ & $9(6.5)$ & $140(11.0)$ & $9(7.0)$ & \\
\hline Intermediate & $2418(43.5)$ & $15(45.5)$ & $318(46.0)$ & $1449(44.0)$ & $70(50.4)$ & $514(40.4)$ & $52(40.3)$ & \\
\hline High & $2586(46.5)$ & $15(45.5)$ & $313(45.3)$ & $1511(45.8)$ & $60(43.2)$ & 619 (48.6) & $68(52.7)$ & 0.15 \\
\hline Follow time, years, mean (SD) & $20.0(2.8)$ & $19.8(3.1)$ & $20.0(2.8)$ & $20.1(2.7)$ & $20.0(2.5)$ & $19.9(2.9)$ & $19.3(3.4)$ & 0.007 \\
\hline \multicolumn{9}{|l|}{ Cognitive function, mean (SD) } \\
\hline Reasoning (range 0-65) & $48.6(9.7)$ & $49.2(10.1)$ & $48.7(9.5)$ & $48.3(9.8)$ & $49.4(9.2)$ & $49.1(9.4)$ & $48.3(10.3)$ & 0.29 \\
\hline Memory (range 0-20) & $7.1(2.3)$ & $8.1(2.7)$ & $6.8(2.3)$ & $7.1(2.3)$ & $6.9(2.5)$ & $7.1(2.3)$ & $6.9(2.4)$ & 0.010 \\
\hline Phonemic fluency (range 0-35) & $17.3(4.3)$ & $18.8(4.3)$ & $17.2(4.4)$ & $17.2(4.2)$ & $17.1(4.5)$ & $17.5(4.5)$ & $16.5(4.3)$ & 0.03 \\
\hline Semantic fluency (range 0-35) & $16.9(4.0)$ & $18.5(4.0)$ & $17.0(4.2)$ & $16.9(4.0)$ & $16.8(3.6)$ & $17.0(4.0)$ & $16.9(4.0)$ & 0.45 \\
\hline Standardized global cognitive score & $-0.0(1.0)$ & $0.4(1.2)$ & $-0.0(1.0)$ & $-0.0(1.0)$ & $-0.0(1.0)$ & $0.1(1.0)$ & $-0.1(1.1)$ & 0.10 \\
\hline
\end{tabular}


Table 2 Baseline characteristics according to dementia and mortality status at the end of the follow-up

\begin{tabular}{|c|c|c|c|c|c|c|}
\hline \multirow[t]{3}{*}{ Sample characteristics } & \multicolumn{3}{|c|}{ Dementia over follow-up } & \multicolumn{3}{|c|}{ Mortality over follow-up } \\
\hline & No & Yes & $p$ value & No & Yes & $p$ value \\
\hline & $(n=5251)$ & $(n=310)$ & & $(n=4783)$ & $(n=778)$ & \\
\hline Age, years, mean (SD) & $55.2(5.8)$ & $60.9(5.0)$ & $<0.001$ & $54.9(5.7)$ & $59.6(5.8)$ & $<0.001$ \\
\hline Women, $n$ (\%) & $1403(26.7)$ & 105 (33.9) & 0.006 & $1289(27.0)$ & $219(28.2)$ & 0.49 \\
\hline Married/cohabiting, n (\%) & $4032(76.8)$ & $224(72.3)$ & 0.07 & $3697(77.3)$ & $229(71.9)$ & 0.001 \\
\hline \multicolumn{7}{|l|}{ Education level, $n$ (\%) } \\
\hline Lower secondary school & $2209(42.1)$ & $175(56.5)$ & & $2028(42.4)$ & $356(45.8)$ & \\
\hline Higher secondary school & $1459(27.8)$ & $65(21.0)$ & & $1301(27.2)$ & $223(28.7)$ & \\
\hline University degree or higher & $1583(30.2)$ & $70(22.6)$ & $<0.001$ & $1454(30.4)$ & 199 (25.6) & 0.02 \\
\hline \multicolumn{7}{|l|}{ Occupation, $n(\%)$} \\
\hline Low & $493(9.4)$ & $64(20.7)$ & & $449(9.4)$ & $108(13.9)$ & \\
\hline Intermediate & $2297(43.7)$ & $121(39.0)$ & & 2085 (43.6) & 333 (42.8) & \\
\hline High & $2461(46.9)$ & $125(40.3)$ & $<0.001$ & $2249(47.0)$ & $337(43.3)$ & $<0.001$ \\
\hline \multicolumn{7}{|l|}{ Cognitive function, mean (SD) } \\
\hline Reasoning & $48.8(9.5)$ & $44.8(11.1)$ & $<0.001$ & $48.9(9.5)$ & $46.4(10.5)$ & $<0.001$ \\
\hline Memory & $7.1(2.3)$ & $6.0(2.2)$ & $<0.001$ & $7.2(2.3)$ & $6.4(2.3)$ & $<0.001$ \\
\hline Phonemic fluency & $17.3(4.3)$ & $15.8(4.4)$ & $<0.001$ & $17.4(4.3)$ & $16.3(4.2)$ & $<0.001$ \\
\hline Semantic fluency & $17.0(4.0)$ & $15.2(4.0)$ & $<0.001$ & $17.1(4.0)$ & $16.2(4.2)$ & $<0.001$ \\
\hline Standardized global cognitive score & $0.0(1.0)$ & $-0.5(1.0)$ & $<0.001$ & $0.0(1.0)$ & $-0.3(1.0)$ & $<0.001$ \\
\hline \multicolumn{7}{|l|}{ APOE genotype, $n(\%)$} \\
\hline$\varepsilon 2 \varepsilon 2$ & $33(0.6)$ & $0(0.0)$ & & $28(0.6)$ & $5(0.6)$ & \\
\hline$\varepsilon 2 \varepsilon 3$ & $664(12.7)$ & $27(8.7)$ & & $593(12.4)$ & $98(12.6)$ & \\
\hline$\varepsilon 3 \varepsilon 3$ & $3156(60.1)$ & $140(45.2)$ & & $2856(59.7)$ & $440(56.6)$ & \\
\hline$\varepsilon 2 \varepsilon 4$ & $131(2.5)$ & $8(2.6)$ & & $117(2.5)$ & $22(2.8)$ & \\
\hline$\varepsilon 3 \varepsilon 4$ & $1162(22.1)$ & $111(35.8)$ & & $1082(22.6)$ & 191 (24.6) & \\
\hline$\varepsilon 4 \varepsilon 4$ & $105(2.0)$ & $24(7.7)$ & $<0.001$ & $107(2.2)$ & $22(2.8)$ & 0.60 \\
\hline
\end{tabular}

Table 3 Fine and Gray sub-distribution hazard ratios (SHR) for incidence of dementia according to APOE genotype, taking into account the competing risk of death

\begin{tabular}{|c|c|c|c|c|c|c|}
\hline \multirow[t]{2}{*}{$A P O E$ genotype } & \multirow[t]{2}{*}{$N$ (total) } & \multirow[t]{2}{*}{$\%$ Dementia } & \multicolumn{2}{|l|}{ Model $1^{a}$} & \multicolumn{2}{|l|}{ Model $2^{b}$} \\
\hline & & & SHR $(95 \% \mathrm{Cl})$ & $p$ value & SHR $(95 \% \mathrm{Cl})$ & $p$ value \\
\hline Non-ع4 carrier & 4020 & 4.1 & 1 (ref.) & - & 1 (ref.) & - \\
\hline દ4 heterozygote & 1412 & 8.4 & $2.19(1.73,2.77)$ & $<0.001$ & $2.22(1.75,2.81)$ & $<0.001$ \\
\hline ¿4 homozygote & 129 & 18.6 & $5.97(3.85,9.28)$ & $<0.001$ & $6.24(3.99,9.77)$ & $<0.001$ \\
\hline દ2દ2/દ2દ3 & 724 & 3.7 & $0.81(0.54,1.21)$ & 0.30 & $0.82(0.54,1.23)$ & 0.33 \\
\hline$\varepsilon 3 \varepsilon 3$ & 3296 & 4.2 & 1 (ref.) & - & 1 (ref.) & - \\
\hline$\varepsilon 2 \varepsilon 4$ & 139 & 5.8 & $1.48(0.73,3.00)$ & 0.27 & $1.51(0.74,3.07)$ & 0.25 \\
\hline$\varepsilon 3 \varepsilon 4$ & 1273 & 8.7 & $2.17(1.69,2.78)$ & $<0.001$ & $2.21(1.72,2.83)$ & $<0.001$ \\
\hline$\varepsilon 4 \varepsilon 4$ & 129 & 18.6 & $5.75(3.69,8.98)$ & $<0.001$ & $6.01(3.82,9.46)$ & $<0.001$ \\
\hline
\end{tabular}

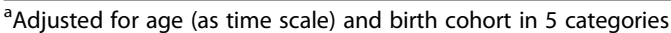

${ }^{\mathrm{b}}$ Adjusted for age, birth cohort, sex, level of education, marital status, and occupation 

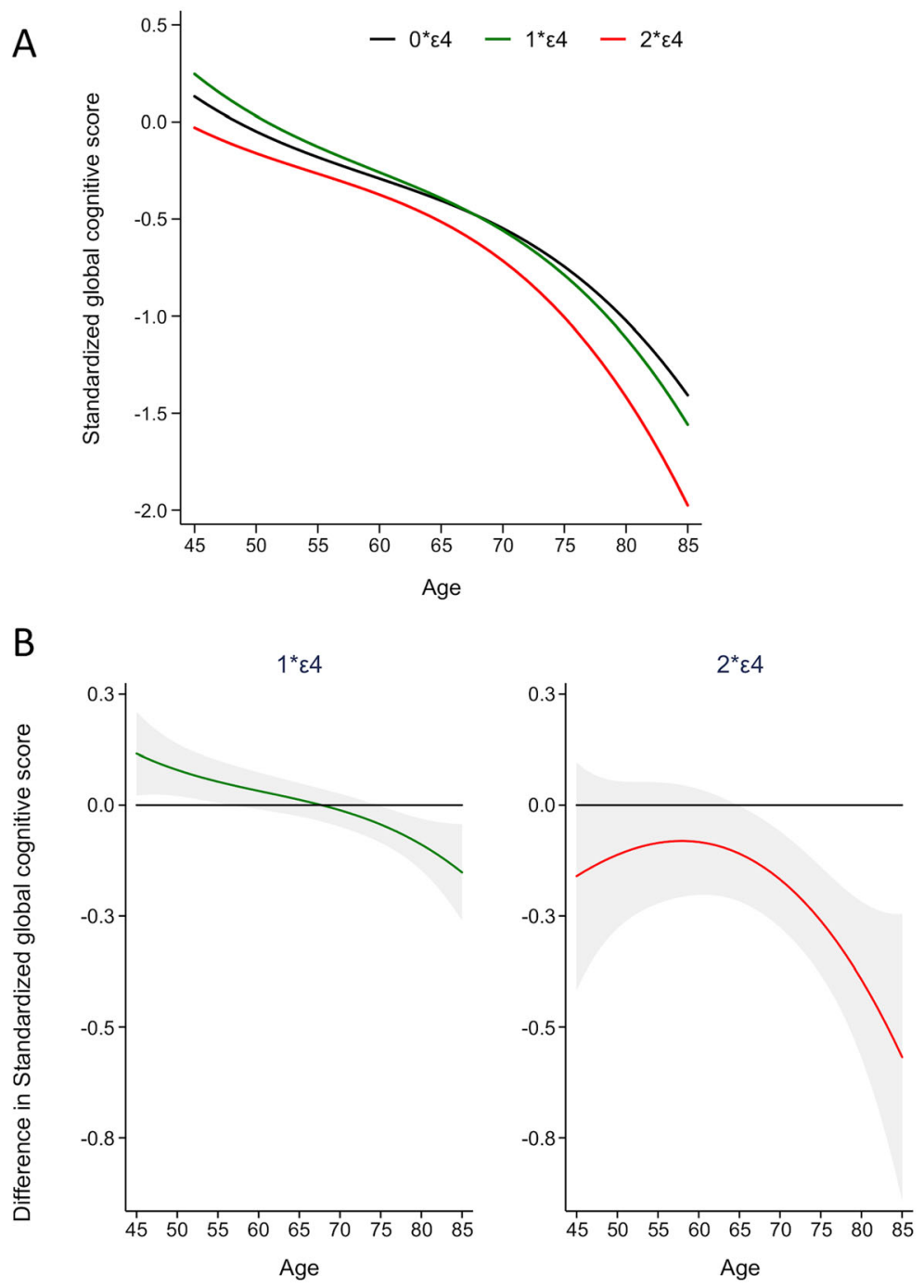

Fig. 2 Global cognitive score over the adult life course as a function of number of APOE $\varepsilon 4$ alleles. Analysis are undertaken using joint models, using age as time scale (age, $\mathrm{age}^{2}$, and $\mathrm{age}^{3}$ ), and adjusted for sex, marital status, education level, occupation, and their interactions with time. a Global cognitive score trajectories according to the number of APOE $\varepsilon 4$ alleles. $\mathbf{b}$ Difference in global cognitive score in APOE $\varepsilon 4$ homozygotes and heterozygotes compared to non- $\varepsilon 4$ carriers. Gray shaded intervals represent $95 \%$ confidence intervals of the estimates

performance after the age of 80 compared to $\varepsilon 3 / \varepsilon 3$ ( $p=$ $0.04)$, while no differences were observed for $\varepsilon 2 / \varepsilon 4$ individuals. In sensitivity analysis, we reran the joint models after exclusion of 208 participants with incident dementia over the follow-up and found similar results.

Further analyses were undertaken using performance on individual cognitive tests between the ages of 45 and 85 years as the outcome; results are shown in Table 4 and Fig. 3. Participants who were $\varepsilon 4$ heterozygous had better performance on reasoning and phonemic fluency than non- $\varepsilon 4$ carriers at younger ages and poorer performance on memory, reasoning, and semantic fluency at older ages. For all cognitive tests, $\varepsilon 4$ homozygotes showed lower cognitive performance at older ages.

\section{Discussion}

This longitudinal study based on 5561 men and women presents two key findings. One, we confirmed that the $\varepsilon 4$ allele of $A P O E$ is associated with accelerated cognitive decline over the adult life course, not only homozygotes but also heterozygotes, irrespective of dementia occurrence. Compared to non- $\varepsilon 4$ carriers, worse cognitive performance among $\varepsilon 4$ carriers was noticeable from 65 years of age for homozygotes and from 75 years for heterozygotes. Two, we found a seemingly paradoxical effect of $A P O E \& 4$ in heterozygotes who had better performance on the global cognitive score than non- $\varepsilon 4$ carriers up to the age of 55 years. More fine grained analyses suggested that better cognitive performance in the 


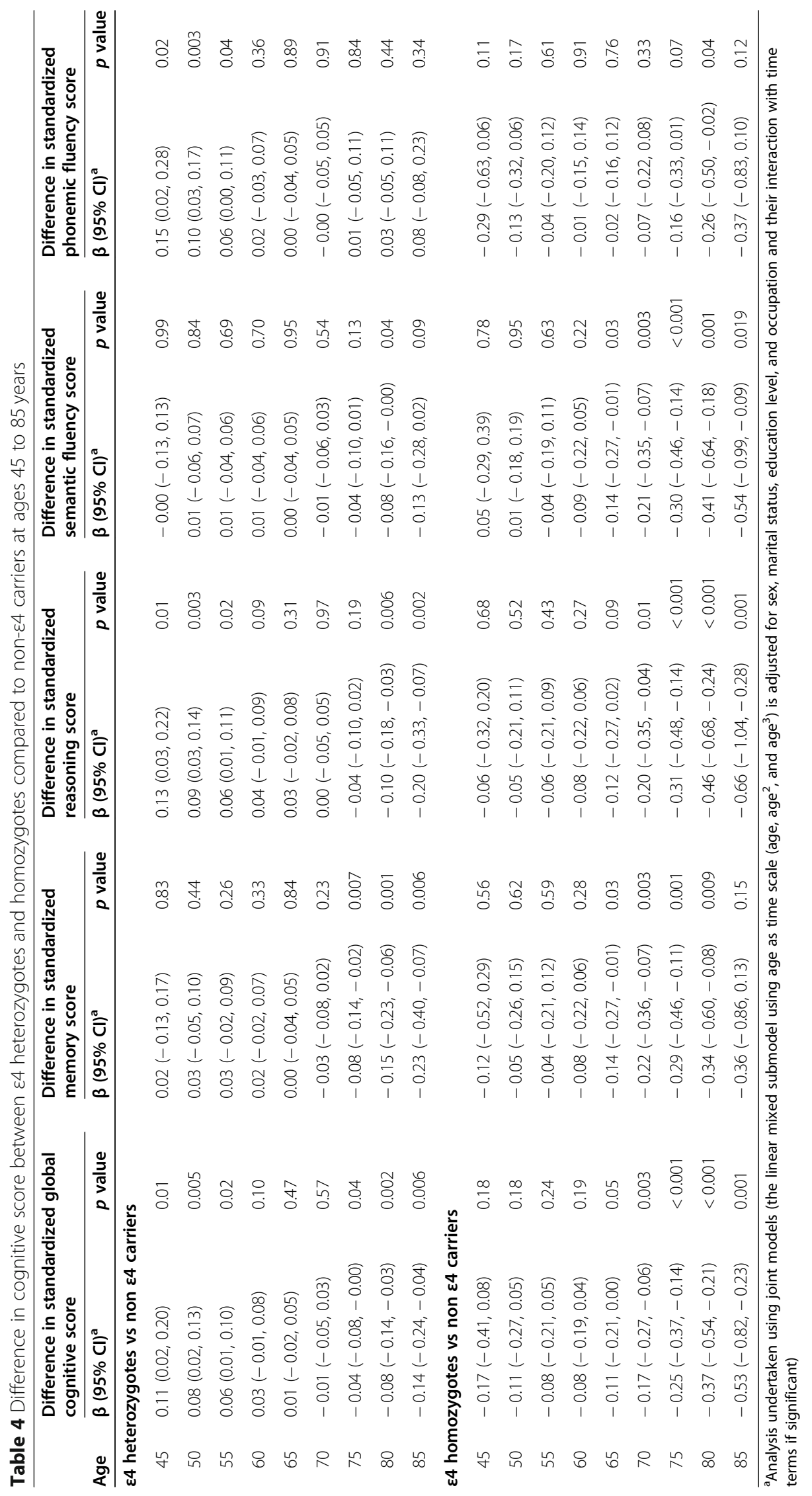



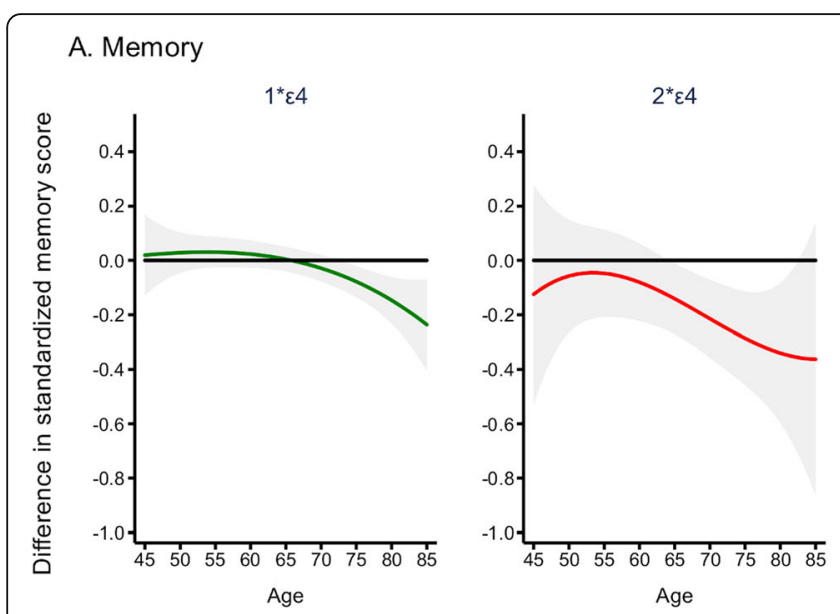

B. Reasoning
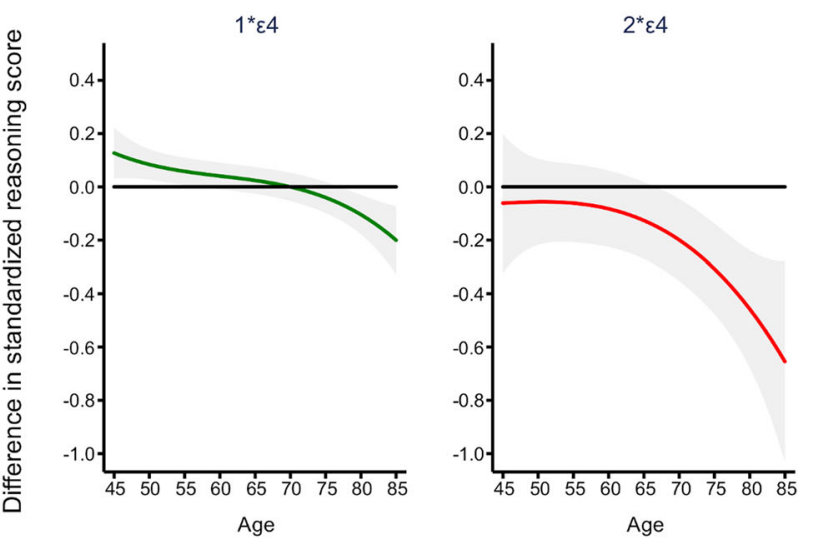

C. Semantic Fluency
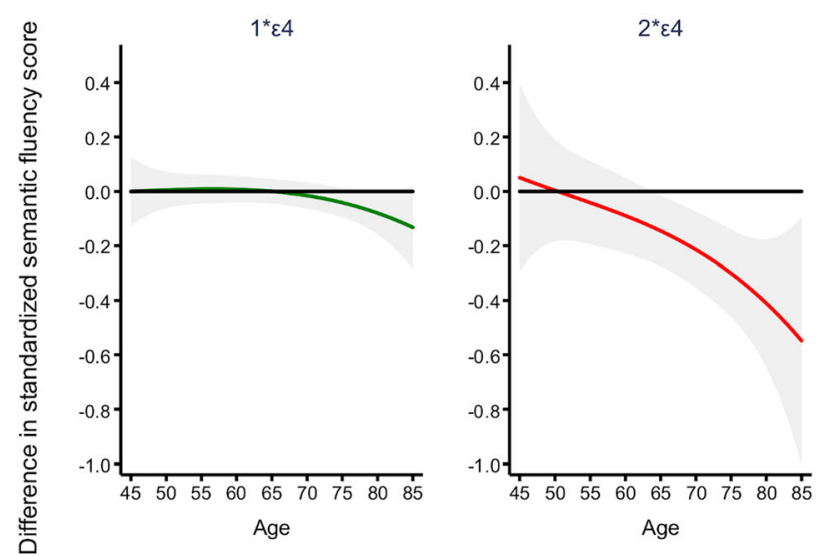

D. Phonemic Fluency

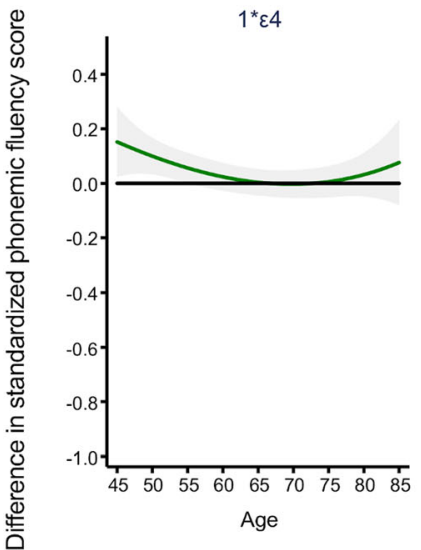

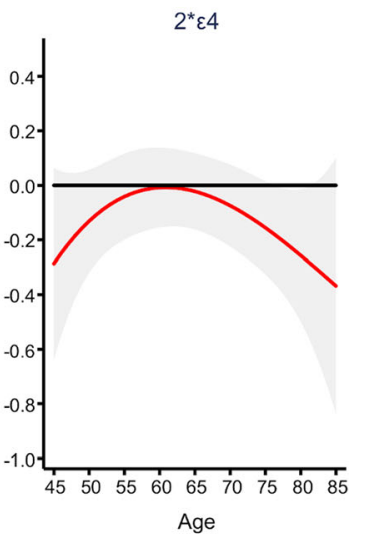

Fig. 3 Difference in standardized cognitive tests of memory (a), reasoning (b), semantic (c), and phonemic fluency (d) in APOE $\varepsilon 4$ heterozygotes and homozygotes compared to non- $\varepsilon 4$ carriers. Analysis are undertaken using joint models, using age as time scale (age, age ${ }^{2}$, and age ${ }^{3}$ ), and adjusted for sex, marital status, education level, occupation, and their interactions with time. Gray-shaded intervals represent $95 \%$ confidence intervals of the estimates

younger $\varepsilon 4$ heterozygotes was primarily in tests that tap into executive function (reasoning, phonemic fluency). These results taken together provide support for the antagonistic pleiotropic hypothesis as cognitive performance was better at younger ages in $A P O E \varepsilon 4$ heterozygotes and both heterozygous and homozygous $A P O E$ \&4 carriers also had higher risk of dementia at older ages. The strength of the associations with cognitive performance was comparable to that in previous studies which did not include dementia follow-up [30, 31].

Few previous studies have examined the association between $A P O E$ genotype and cognitive decline over the adult life course as most studies are based on older adults who were followed for cognitive outcomes for less than 10 years [13-15, 32]. Several studies did not distinguish between $\varepsilon 4$ heterozygotes and homozygotes [32-34], and studies making this distinction did not find evidence of faster cognitive decline in $\varepsilon 4$ heterozygous carriers [13-15]. In the Arizona
APOE cohort $(n=815)$ with mean age of participants at baseline being 60.1 years and mean follow-up 5 years, $\varepsilon 4$ homozygous had a more pronounced cognitive decline than $\varepsilon 4$ non-carriers but no significant difference was observed for $\varepsilon 4$ heterozygotes [14]. In another study on 621 participants (mean age 58 years, follow-up 6 years), a more pronounced decline was likewise observed only for $\varepsilon 4$ homozygotes [13]. This was also the case in the MRC National Survey of Health and Development cohort study [15]. It is possible that the limited follow-up in these studies did not allow the age-dependent association between heterozygous $A P O E \varepsilon 4$ and cognitive function to be detected. Such information is important as $\varepsilon 4$ homozygotes represent a small proportion of the population but the prevalence of $\varepsilon 4$ heterozygotes is over $20 \%$.

The mechanisms underlying the association between $A P O E \& 4$ and cognitive decline remain poorly understood; further research using $\mathrm{AD}$ biomarkers may 
provide insight into these mechanisms. Several studies have shown that APOE \&4 carriers in non-demented population have an increased incidence of beta-amyloid PET positivity compared to non-carriers [35]. A recent amyloid PET based study suggests that APOE $\varepsilon 4$ carriers may reach abnormal level of neocortical $A \beta$-amyloid at the age of 63 compared to 78 years in non-carriers [36], suggesting a 15 -year difference between these 2 categories. Accumulation of protein Tau is also likely to play a role as a study showed an increase of tau PET uptake in the entorhinal cortex and hippocampus among $\varepsilon 4$ carriers independently of $A \beta$ load [37]. Poorer cognition has been related to tau PET accumulation, even among $\mathrm{A} \beta$-negative $\varepsilon 4$ carriers [38], suggesting that the APOE $\varepsilon 4$ allele may enhance the vulnerability to progressive tau accumulation in the AD spectrum [39].

To our knowledge, ours is the first study to show that $\varepsilon 4$ allele heterozygosity may have a differential effect on cognition as a function of age. The long follow-up allowed us to show that compared to non $\varepsilon 4$ carriers, $\varepsilon 4$ heterozygotes had poorer cognitive scores after the age of 75 years old but better performance before the age of 55. Few cross-sectional or short longitudinal studies have been able to show better cognitive performance in young $\varepsilon 4$ carriers $[17,34,40]$. An experimental study on mice found that $\varepsilon 4$ allele was initially associated with better spatial memory in young animals and then deleterious effect at later ages [41]. Interestingly, we found that the early cognitive benefit associated with the $\varepsilon 4$ allele is mainly in executive function (reasoning, phonemic fluency), while no difference was observed for memory or semantic tasks which involve temporal and temporal intern area. This is consistent with several metabolic PET imaging studies which have found that APOE $\varepsilon 4$ allele in the normal population is associated with a decrease in metabolism in the posterior regions of the brain (parietal, posterior cingulate), but also with an increase of metabolism in the anterior frontal area [42, 43]. A recent meta-analysis of studies on the age range from 2 to 40 years did not find differences in cognitive performance between $A P O E \& 4$ carriers and noncarriers, with the authors concluding that there was no support for the antagonistic pleiotropic hypothesis [20]. As this meta-analysis combined APOE \&4 homozygotes and heterozygotes, the results are not directly comparable to our study. It is also possible that the effect we observed is not innate but acquired and may appear after the 4th decade of life in reaction of early biochemical processes involved in neurodegenerative diseases, like the onset of beta-amyloid deposition observed in the posterior area of the brain in AD pathology [44].

It is unclear why $A P O E \varepsilon 4$ has remained highly prevalent in the population over the course of evolution despite its deleterious effects on dementia and cardiovascular health [45]. Our results show that $A P O E \varepsilon 4$ could confer a cognitive advantage before the age of 55 years, especially in reasoning and psychomotor speed, which could have contributed to the preservation of this allele over the long course of premodern human history when mean life expectancy was lower than 50 years [46]. Another recent study also found that $A P O E \& 4$ carriers may particularly benefit of protective effect on the brain connectivity of the physical activity [47].

\section{Limitations}

This study has several strengths, including its large sample size and the long follow-up. We also used appropriate statistical methods, i.e., joint modeling, to take into account the potential selection bias arising from mortality, dementia, and drop-out. Despite the long duration of follow-up, we were not able to model the relationship before the age of 45 years and thus examine whether the cognitive benefits related to $A P O E \& 4$ are evident earlier in the life course. A further limitation is that we were not able to completely rule out the role of $\mathrm{AD} /$ dementia, in particular preclinical dementia, in cognitive decline observed in APOE $\varepsilon 4$ carriers. To limit this bias, we censored individuals at diagnosis of dementia in our primary analyses and then tested the robustness of our results by completely excluding participants diagnosed with dementia over the follow-up. The lack of preclinical markers of $\mathrm{AD} /$ dementia biomarkers is a limitation. Ongoing advances in plasma-based biomarkers will be an important opportunity in the future to better understand the mechanisms underlying these associations.

\section{Conclusions}

In summary, our results show some support for a complex antagonist pleiotropic effect of $A P O E \& 4$ heterozygosity during adult life course and confirm that both heterozygous and homozygous $\varepsilon 4$ carriers have poorer cognition at older ages. Further research using different population settings in similar life course studies is needed to test the generalizability of our findings.

\section{Supplementary Information}

The online version contains supplementary material available at https://doi. org/10.1186/s13195-020-00740-0.

Additional file 1: Table S1. Baseline cognitive function as a function of APOE genotype with $\varepsilon 3 \varepsilon 3$ as the reference.

Additional file 2: Table S2. Baseline characteristics of participants as a function of the number of waves of cognitive data over the follow-up.

Additional file 3: Table S3. Difference in Standardized Global Cognitive Score between 45 and 85 Years by APOE in 5 Categories.

\section{Abbreviations}

AD: Alzheimer's disease; APOE: Apolipoprotein E; SD: Standard deviation; SHR: Sub-distribution hazard ratio 


\section{Acknowledgements}

We are grateful to the participants from civil service departments and their welfare, personnel, and establishment officers and all members of the Whitehall II study teams. The Whitehall II study has been supported by grants from the National Institute on Aging, NIH (R01AG056477, RF1AG062553), UK Medical Research Council (R024227, S011676), and the British Heart Foundation (RG/16/11/32334).

\section{Authors' contributions}

A.G.-M., A.S.-M., and J.D. developed the hypothesis and study design. A.G.-M. and A.D. performed the statistical analysis. A.G.-M. and J.D. wrote the first and successive draft of the manuscript. All authors contributed to review of manuscript and approved the final version to be published. A.S.-M. and M.K. obtained funding. A.G.-M., A.D., and J.D. had full access to the data and take responsibility for the integrity of the data and the accuracy of the data analysis.

\section{Funding}

Mika Kivimaki is supported by the Medical Research Council (K013351, R024227, S011676), UK, NordForsk, the Academy of Finland (311492), and Helsinki Institute of Life Science. Séverine Sabia is supported by the French National Research Agency (ANR-19-CE36-0004-01). Archana Singh-Manoux is supported by the National Institute on Aging, NIH (R01AG056477,

RF1AG062553). The funding had no role in the design of the study and collection, analysis, interpretation of data, and writing of the manuscript.

\section{Availability of data and materials}

Bona fide researchers can apply to access Whitehall II data via the national dementia platform (https://www.dementiasplatform.uk/) or the study specific mechanism, details on https://www.uclac.uk/epidemiology-health-care/ research/epidemiology-and-public-health/research/whitehall-ii/data-sharing.

\section{Ethics approval and consent to participate}

Participant consent and research ethics approvals are renewed at each contact; the latest approval was by the National Health Service (NHS) London-Harrow Research Ethics Committee, reference number 85/0938. All participants provided written, informed consent.

\section{Consent for publication}

Not applicable.

\section{Competing interests}

The authors declare no competing interest.

\section{Author details}

${ }^{1}$ Université de Paris, Inserm U1153, Epidemiology of Ageing and Neurodegenerative Diseases, Paris, France. ${ }^{2}$ Department of Epidemiology and Public Health, University College London, London, UK. ${ }^{3}$ Cognitive Neurology Center, Lariboisiere - Fernand Widal Hospital, AP-HP, Université de Paris, 200 rue du Faubourg Saint Denis, 75010 Paris, France.

\section{Received: 21 September 2020 Accepted: 7 December 2020} Published online: 04 January 2021

\section{References}

1. Dumurgier J, Tzourio C. Epidemiology of neurological diseases in older adults. Rev Neurol (Paris). 2020;176:642-8.

2. Corbo RM, Scacchi R. Apolipoprotein E (APOE) allele distribution in the world. Is APOE*4 a 'thrifty' allele? Ann Hum Genet. 1999;63:301-10.

3. Saddiki $H$, Fayosse $A$, Cognat $E$, et al. Age and the association between apolipoprotein E genotype and Alzheimer disease: a cerebrospinal fluid biomarker-based case-control study. Plos Med. 2020;17:e1003289.

4. Conejero-Goldberg C, Gomar JJ, Bobes-Bascaran T, et al. APOE2 enhances neuroprotection against Alzheimer's disease through multiple molecular mechanisms. Mol Psychiatry. 2014;19:1243-50.

5. Konijnenberg E, Tijms BM, Gobom J, et al. APOE $\varepsilon 4$ genotype-dependent cerebrospinal fluid proteomic signatures in Alzheimer's disease. Alzheimers Res Ther. 2020;12:65.

6. Yi D, Lee Y, Byun MS, et al. Synergistic interaction between APOE and family history of Alzheimer's disease on cerebral amyloid deposition and glucose metabolism. Alzheimers Res Ther. 2018;10:84.
7. Sun X, Dong C, Levin B, et al. APOE epsilon4 carriers may undergo synaptic damage conferring risk of Alzheimer's disease. Alzheimers Dement. 2016;12: 1159-66.

8. Wadhwani AR, Affaneh A, Van Gulden S, Kessler JA. Neuronal apolipoprotein E4 increases cell death and phosphorylated tau release in Alzheimer disease. Ann Neurol. 2019;85:726-39.

9. Skrobot OA, Mcknight AJ, Passmore PA, et al. A validation study of vascular cognitive impairment genetics meta-analysis findings in an independent collaborative cohort. J Alzheimers Dis. 2016;53:981-9.

10. Rongve A, Witoelar A, Ruiz A, et al. GBA and APOE epsilon4 associate with sporadic dementia with Lewy bodies in European genome wide association study. Sci Rep. 2019;9:7013.

11. O'Donoghue MC, Murphy SE, Zamboni G, Nobre AC, Mackay CE. APOE genotype and cognition in healthy individuals at risk of Alzheimer's disease: a review. Cortex. 2018;104:103-23.

12. Salvato G. Does apolipoprotein E genotype influence cognition in middleaged individuals? Curr Opin Neurol. 2015;28:612-7.

13. Caselli RJ, Dueck AC, Locke DE, et al. Longitudinal modeling of frontal cognition in APOE epsilon4 homozygotes, heterozygotes, and noncarriers. Neurology. 2011;76:1383-8.

14. Caselli RJ, Dueck AC, Osborne D, et al. Longitudinal modeling of age-related memory decline and the APOE epsilon4 effect. N Engl J Med. 2009;361:255-63.

15. Rawle MJ, Davis D, Bendayan R, Wong A, Kuh D, Richards M. Apolipoprotein-E (Apoe) epsilon4 and cognitive decline over the adult life course. Transl Psychiatry. 2018:8:18.

16. Yu YW, Lin CH, Chen SP, Hong CJ, Tsai SJ. Intelligence and event-related potentials for young female human volunteer apolipoprotein E epsilon4 and non-epsilon4 carriers. Neurosci Lett. 2000;294:179-81.

17. Mondadori CR, de Quervain DJ, Buchmann A, et al. Better memory and neural efficiency in young apolipoprotein E epsilon4 carriers. Cereb Cortex. 2007;17:1934-47.

18. Alexander DM, Williams LM, Gatt JM, et al. The contribution of apolipoprotein E alleles on cognitive performance and dynamic neural activity over six decades. Biol Psychol. 2007;75:229-38.

19. Bussy A, Snider BJ, Coble D, et al. Effect of apolipoprotein E4 on clinical, neuroimaging, and biomarker measures in noncarrier participants in the Dominantly Inherited Alzheimer Network. Neurobiol Aging. 2019;75:42-50.

20. Weissberger GH, Nation DA, Nguyen CP, Bondi MW, Han SD. Meta-analysis of cognitive ability differences by apolipoprotein e genotype in young humans. Neurosci Biobehav Rev. 2018;94:49-58.

21. Williams GC. Pleiotropy, natural selection, and the evolution of senescence. Evolution. 1957;11:398-411.

22. Tuminello ER, Han SD. The apolipoprotein E antagonistic pleiotropy hypothesis: review and recommendations. Int J Alzheimers Dis. 2011;2011: 726197.

23. Han SD, Bondi MW. Revision of the apolipoprotein E compensatory mechanism recruitment hypothesis. Alzheimers Dement. 2008;4:251-4.

24. Marmot MG, Smith GD, Stansfeld S, et al. Health inequalities among British civil servants: the Whitehall II study. Lancet. 1991;337:1387-93.

25. Heim AW, editor. AH 4 group test of general intelligence. Windsor: NFERNelsonPublishing Company Ltd.; 1970.

26. Wilson RS, Leurgans SE, Boyle PA, Schneider JA, Bennett DA. Neurodegenerative basis of age-related cognitive decline. Neurology. 2010; 75:1070-8.

27. Sabia S, Fayosse A, Dumurgier J, et al. Association of ideal cardiovascular health at age 50 with incidence of dementia: 25 year follow-up of Whitehall II cohort study. BMJ. 2019;366:14414.

28. Sabia S, Kivimaki M, Kumari M, Shipley MJ, Singh-Manoux A. Effect of Apolipoprotein E epsilon4 on the association between health behaviors and cognitive function in late midlife. Mol Neurodegener. 2010;5:23.

29. Fine JP, Gray RJ. A proportional hazards model for the subdistribution of a competing risk. J Am Stat Assoc. 1999;94:496-509.

30. Rasmussen KL, Tybjaerg-Hansen A, Nordestgaard BG, Frikke-Schmidt R. Absolute 10-year risk of dementia by age, sex and APOE genotype: a population-based cohort study. CMAJ. 2018;190:E1033-e41.

31. Qian J, Wolters FJ, Beiser A, et al. APOE-related risk of mild cognitive impairment and dementia for prevention trials: an analysis of four cohorts. PLoS Med. 2017:14:e1002254.

32. Yaffe K, Cauley J, Sands L, Browner W. Apolipoprotein E phenotype and cognitive decline in a prospective study of elderly community women. Arch Neurol. 1997;54:1110-4. 
33. Lim YY, Ellis KA, Pietrzak RH, et al. Stronger effect of amyloid load than APOE genotype on cognitive decline in healthy older adults. Neurology. 2012;79:1645-52.

34. Schultz MR, Lyons MJ, Franz CE, et al. Apolipoprotein E genotype and memory in the sixth decade of life. Neurology. 2008;70:1771-7.

35. Jansen WJ, Ossenkoppele R, Knol DL, et al. Prevalence of cerebral amyloid pathology in persons without dementia: a meta-analysis. Jama. 2015;313: 1924-38.

36. Burnham SC, Laws SM, Budgeon CA, et al. Impact of APOE- $\varepsilon 4$ carriage on the onset and rates of neocortical $A \beta$-amyloid deposition. Neurobiol Aging. 2020;95:46-55

37. Therriault J, Benedet AL, Pascoal TA, et al. Association of Apolipoprotein E $\varepsilon 4$ with medial temporal tau independent of amyloid-B. JAMA Neurol. 2020; 77:470-9.

38. Weigand AJ, Thomas KR, Bangen KJ, et al. APOE interacts with tau PET to influence memory independently of amyloid PET in older adults without dementia. Alzheimers Dement. 2020. https://doi.org/10.1002/alz.12173.

39. Baek MS, Cho H, Lee HS, Lee JH, Ryu YH, Lyoo CH. Effect of APOE $\varepsilon 4$ genotype on amyloid- $\beta$ and tau accumulation in Alzheimer's disease. Alzheimers Res Ther. 2020;12:140.

40. Jochemsen HM, Muller M, van der Graaf Y, Geerlings MI. APOE epsilon4 differentially influences change in memory performance depending on age. The SMART-MR study. Neurobiol Aging. 2012;33:832.e15-22.

41. Moreau PH, Bott JB, Zerbinatti C, et al. ApoE4 confers better spatial memory than apoE3 in young adult hAPP-Yac/apoE-TR mice. Behav Brain Res. 2013; 243:1-5.

42. Yi D, Lee DY, Sohn BK, et al. Beta-amyloid associated differential effects of APOE epsilon4 on brain metabolism in cognitively normal elderly. Am J Geriatr Psychiatry. 2014;22:961-70.

43. Rubinski A, Franzmeier N, Neitzel J, Ewers M. FDG-PET hypermetabolism is associated with higher tau-PET in mild cognitive impairment at low amyloid-PET levels. Alzheimers Res Ther. 2020;12:133.

44. Palmqvist S, Scholl M, Strandberg O, et al. Earliest accumulation of betaamyloid occurs within the default-mode network and concurrently affects brain connectivity. Nat Commun. 2017:8:1214.

45. Abondio P, Sazzini M, Garagnani P, et al. The genetic variability of APOE in different human populations and its implications for longevity. Genes (Basel). 2019;10:222.

46. Finch CE. Evolution in health and medicine Sackler colloquium: evolution of the human lifespan and diseases of aging: roles of infection, inflammation, and nutrition. Proc Natl Acad Sci U S A. 2010;107(Suppl 1):1718-24.

47. de Frutos-Lucas J, Cuesta P, López-Sanz D, et al. The relationship between physical activity, apolipoprotein E $\varepsilon 4$ carriage, and brain health. Alzheimers Res Ther. 2020;12:48.

\section{Publisher's Note}

Springer Nature remains neutral with regard to jurisdictional claims in published maps and institutional affiliations.

Ready to submit your research? Choose BMC and benefit from:

- fast, convenient online submission

- thorough peer review by experienced researchers in your field

- rapid publication on acceptance

- support for research data, including large and complex data types

- gold Open Access which fosters wider collaboration and increased citations

- maximum visibility for your research: over $100 \mathrm{M}$ website views per year

At $\mathrm{BMC}$, research is always in progress.

Learn more biomedcentral.com/submissions 